\title{
Customer support services: more than administrative support - it has to be strategic!
}

The world as many of us have known it for decades began to change dramatically by the beginning of 2020. In a matter of weeks, we were in the midst of a worldwide pandemic. Consumers who had been going about their daily lives were faced, somewhat suddenly, with fears of product shortages, self-quarantines and shelter in place orders. \#socialdistancing became a moniker that appeared in conversations, both online and offline. Many of these consumers may have had hotel, airline, rental car and event reservations (for example) for which they had already paid. Customer support services suddenly became front and center for everyone - both as customers and as purveyors.

Customer inboxes became flooded with emails detailing what companies were doing in terms of customer safety and that the companies were there to assist as needed (e.g. not charging cancellation/rebooking fees). At the same time, worried customers barraged company websites and telephone lines as they tried to figure out what to do. These were uncertain times, and no one had a template for what to do in such a time of crisis. Traditionally empowered customers felt helpless, and customer support services were needed at an unprecedented pace. This was not the time for $\mathrm{B} 2 \mathrm{~B}$ or $\mathrm{B} 2 \mathrm{C}$ companies to think of customer support as an administrative cost center, it was time for companies to engage in customer support strategically.

In their article, "Repositioning the Customer Support Services: The Next Frontier of Competitive Advantage," Sheth, Jain and Ambika focus on the need for strategic customer support and posit that a company's customer support strategy should be built with the objective of both customer and employee value. Consistent with the adage, happy employees lead to happy customers, customer centricity is achieved when interactions between the company and the customer are positive, even in dire situations. In the Sheth et al. model of strategic customer support, the long-term gain is that customer support becomes a profit center, ultimately leading to a competitive advantage. The logical flow is that those happy employees will engage with (potentially unhappy) customers and those (ultimately) happy customers will lead to company loyalty and higher customer lifetime value - and, thus, longterm profitability. Given this potential long-term gain, there should be no doubt that customer support is a key strategic asset to the company and should be positioned accordingly within the organization.

Sheth et al. identified seven key steps important for a company transforming its administrative customer support group to a customer centric, profit generating strategic function. The power of each of these steps, either as standalone or combinatorial will have to be explored via considerable research. I can see an entire research stream arising from the work Sheth, Jain and Ambika have offered.

In the midst of the worldwide pandemic crisis, I suspect that customer support is likely more critical than ever. Are any of the seven steps within the profit center more (less) important than others in terms in times of crisis? For example, does the fact that an airline has a Senior Vice President of Customer Experience who serves as a spokesperson for the airline during times of crisis matter more (less) than the frontline employee at a rental car company who tells a customer over the telephone that "I promise from the bottom of my

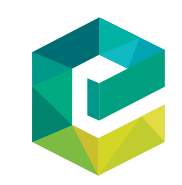

European Journal of Marketing Vol. 54 No. 7,2020 
heart to rectify the problem" (when a customer's credit card was billed a rental fee of US $\$ 4,455$ instead of the original rate of US $\$ 1,570$ because she returned the rental car eight days early due to needing to get home to her family during a pandemic)? Does a frontline employee's empathy matter more (less) than the fact that the airline customer can almost immediately see the ticket reimbursement appear in hihe/sher travel bank from an online cancellation? Does the merging of IT and customer support by the airline to show financial reimbursement with an immediate outcome metric outweigh the empathy by the car rental employee, especially since the customer has now had to be on the telephone for an hour to resolve a problem and will not be able to see the credit card refund for five to seven business days?

While I can envision so much that can be explored in terms of customer support as a strategic function during times of crisis, I can also see the importance of understanding this profit center within the context of regular (non-crisis) operations. For example, what is the role of the external environment in terms of generating competitive advantage via another organizational function? Importantly, research that transitions customer support from a cost centre to a profit centre will require cross-functional research teams that include marketers, human resource and business strategy scholars and professionals. At the same time, company financial managers need to expand revenue and cost metrics to embrace the longterm benefits of customer lifetime value. This type of cross-functional collaboration can set the stage for long-term gain in many areas.

Sheth, Jain and Ambika have offered a comprehensive model of customer support services that transitions customer support from an administrative cost centre to a strategic profit centre. In doing so, they have opened the door for both endogenous and exogenous explorations of the role of the repositioned customer support centre, and they have created vast opportunity for cross-functional scholarship that can advance firm understanding of value creation. Importantly, they have articulated the strategic role that customer support can play in a new frontier of competitive advantage.

\section{Victoria Crittenden Babson College, Wellesley, Massachusetts, USA}

